\title{
Cardiovascular Effects of Continuous Propofol Infusion in Horses
}

\author{
Kazuomi OKU ${ }^{1) *}$, Minoru OHTA ${ }^{1)}$, Tomohiro KATOH ${ }^{1)}$, Hidekazu MORIYAMA ${ }^{1)}$, Kanichi KUSANO ${ }^{1)}$ and \\ Toru FUJINAGA ${ }^{2)}$
}

${ }^{1)}$ Racehorse Clinic, Miho Training Center, Japan Racing Association, 2500-2 Oaza-Mikoma, Mihomura, Inashiki-gun, Ibaraki 300-0439 and ${ }^{2}$ Laboratory of Veterinary Surgery, Department of Veterinary Clinical Sciences, Graduate School of Veterinary Medicine, Hokkaido University, Sapporo 060-0818, Japan

(Received 25 March 2005/Accepted 27 March 2006)

ABSTRACT. We examined the influence of propofol infusion on cardiovascular system at the rate of $0.14,0.20 \mathrm{and} 0.30 \mathrm{mg} / \mathrm{kg} / \mathrm{min}$ in $\mathrm{six}$ adult Thoroughbred horses. The cardiovascular parameters were heart rate (HR), mean arterial pressure (MAP), mean right atrial pressure (MRAP), stroke volume (SV), cardiac output (CO), systemic vascular resistance (SVR), pre-ejection period (PEP) and ejection time (ET). In order to keep the ventilation conditions constantly, intermittent positive pressure ventilation was performed, and the partial arterial $\mathrm{CO}_{2}$ pressure was maintained at 45 to $55 \mathrm{mmHg}$ during maintenance anesthesia. SV showed a significant dose-dependent decrease however, CO did not show significant change. SVR decreased significantly at higher dose. PEP was prolonged and PEP/ET increased significantly at the highest dose. From these results, it became clear that SV decreases dose-dependently due to decrease of cardiac contractility during anesthesia with continuous propofol infusion in horses. On the other hand, since MAP and CO did not show significant changes, total intravenous anesthesia with propofol was suggested to be suitable for long-term anesthesia in horses.

KEY WORDS: anesthesia, equine, hemodynamics, propofol, Pulsed Doppler echocardiography.

Propofol (2,6-diisopropylphenol), a new intravenous anesthetic, fulfills many of the conditions required for total intravenous anesthesia (TIVA), i.e. short duration of action with little cumulative effects, easiness of anesthetic depth control and rapid recovery $[13,26]$. For this reason, TIVA using propofol became widely performed in people [7] and animals including horses $[3,10,15,19,20,22]$ in recent years.

Many of anesthetic agents generally induce profound cardiovascular depression $[17,23]$. In human propofol anesthesia, the decreases of arterial blood pressure, stroke volume, cardiac indices, systemic vascular resistance and left cardiac work indices are reported [13]. In horses, the incidence of postanesthetic complications such as myopathy, lameness, and colitis- $\mathrm{X}$ are increased by cardiovascular depression during anesthesia $[12,14]$. Therefore, in order to carry out TIVA safely using this anesthetic agent in horses, it is essential to understand the influence of continuous propofol infusion on the cardiovascular system. However, in horses, there are few reports that evaluate the changes in cardiovascular system during TIVA using propofol based on the measurement of cardiac output (CO) $[2,4,15]$. Moreover, in all of these reports, medetomidine [2, 4] or xylazine [15] was infused in conjunction with propofol, therefore these drugs had no small effect on the results. Additionally, only one report evaluated the relationship between propofol infusion rate and the degree of cardiovascular depression [15]. According to this report, cardiodepressive effect at high propofol infusion rate was masked by the indirect sympathomimetic effects attributed to the dose-

\footnotetext{
* Correspondence to: OKu, K., Clinical Sect., Racehorse Hospital, Ritto Training Center, Japan Racing Association 1028, Misono, Ritto-shi, Shiga 520-3085, Japan.
}

dependent respiratory depression. Thus, the relationship between propofol infusion rate and the degree of cardiovascular depression in horses during TIVA with propofol has not been clarified yet.

The purpose of this study was to collect basic cardiovascular data for TIVA using propofol in horses. Meanwhile, for the purpose, it is desirable not only to maintain, but also to induce anesthesia with propofol alone. However, to ensure safety of horses and personnel, xylazine only was used for premedication. We examined the relationship between propofol infusion rate and cardiovascular parameters such as heart rate (HR), arterial blood pressure and cardiac output (CO) etc. during TIVA after premedication with xylazine under a constant ventilated condition.

\section{MATERIALS AND METHODS}

Horses: Six healthy Thoroughbred horses (4 males and 2 females) were used. Four of these horses were 3 years old and 2 were 4 years old (mean \pm standard deviation (SD), 3.5 \pm 0.6 years old). Their mean weight was $450 \pm 15 \mathrm{~kg}$. Horses were fasted for $12 \mathrm{hr}$ before anesthesia but had free access to water. Experiments were conducted according to the Guidelines for Animal Experiments at Equine Research Institute, Japan Racing Association.

Anesthesia: At 10 min after premedication with xylazine $(1.0 \mathrm{mg} / \mathrm{kg}$; Celactar, Bayer, Tokyo, Japan), each horse was restrained in a swing-door induction system and was induced with the intravenous injection of 1\% propofol $(3.0$ $\mathrm{mg} / \mathrm{kg}$; Rapinovet, Mallinckrodt Veterinary, Mundelein, IL, U.S.A.) solution at a 3 min duration. After horses attained a sternal recumbency, the swing-door was opened and horses were turned to lateral recumbency. Continuously, horses 
Table 1. The sequence of changing propofol infusion rates in each horse

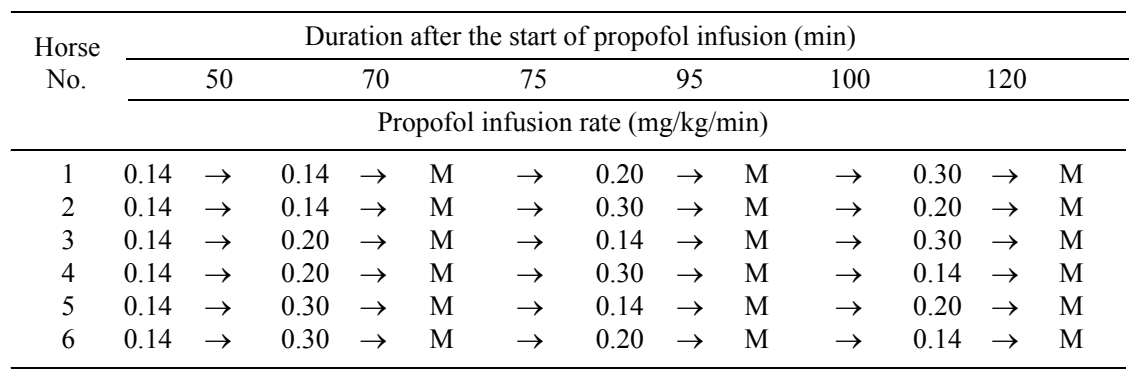

M: measurement of cardiovascular parameters.

were endotracheally intubated and transported to operation room by hoist and placed on a mat in right lateral recumbency.

Following induction by the $3.0 \mathrm{mg} / \mathrm{kg}$ propofol injection, continuous infusion of propofol using intravenous infusion pump (Star-Flow 592, IVAC, San Diego, CA, U.S.A.) was started for maintaining anesthesia. The initial infusion rate was set at $0.14 \mathrm{mg} / \mathrm{kg} / \mathrm{min}$ which is equivalent to the $95 \%$ effective dose of propofol infusion [21]. In order to mitigate the influence of premedication as much as possible, infusion at such rate was continued for $50 \mathrm{~min}$, equal to the systemic half-life of xylazine [11]. Subsequently, the cardiovascular parameters at three infusion rates, $0.14,0.20$ and $0.30 \mathrm{mg} /$ $\mathrm{kg} / \mathrm{min}$, were measured. After maintaining each infusion rate for $20 \mathrm{~min}$, the parameters were measured over approximately $5 \mathrm{~min}$. There are 6 possible sequences of 3 different infusion rates and each of these 6 sequences was applied to each of 6 horses respectively, and randomly (Table 1). During anesthesia, the endotracheal tube was connected to a large animal circle breathing device (MOK94, Silver Medical Co., Tokyo) fitted with a time cycle ventilator (Compos$\beta$ EV, Silver Medical Co.) and supplied with $100 \%$ oxygen. The oxygen flow rate was set at $6 \mathrm{l} / \mathrm{min}$. Horses were allowed to breathe spontaneously for the first 5 min of maintenance anesthesia and respiratory rate was measured to check for apnea more than $30 \mathrm{sec}$. Continuously, ventilation was controlled by intermittent positive pressure ventilation (IPPV) to maintain partial arterial $\mathrm{CO}_{2}$ pressures $\left(\mathrm{PaCO}_{2}\right)$ of 45 to $55 \mathrm{mmHg}$.

Arterial blood gases: Arterial blood gases were measured at 15,30 and 45 min after the start of maintenance anesthesia and at $15 \mathrm{~min}$ after each change of infusion rate. Blood samples for the measurement were collected anaerobically from the arterial catheter and analyzed for $\mathrm{PaO}_{2}$ and $\mathrm{PaCO}_{2}$ using a calibrated arterial blood gas analyzer (288 Blood Gas System, Ciba-Corning, Tokyo).

Mean arterial pressure (MAP) and mean right atrial pressure (MRAP): MAP and MRAP were measured with a $20 \mathrm{G}$ catheter positioned within the facial artery and a SwanGanz catheter (93A-191-8F, Baxter Co., Tokyo) introduced into the right atrium via the left jugular vein, respectively. These catheters were connected to the pressure transducers of the multipurpose monitoring system (M1166A, Hewlett Packard, Palo Alto, CA, U.S.A.). Transducer 0-level was placed at the level of the sternum.

Pulsed Doppler echocardiographgy: HR, stroke volume (SV), pre-ejection period (PEP) and ejection time (ET) were measured using the Pulsed Doppler echocardiography [27]. $\mathrm{CO}$, cardiac index (CI), systemic vascular resistance (SVR) and ratio of pre-ejection period to ejection time (PEP/ET) were calculated from these parameters. The Pulsed Doppler echocardiography was reported to be useful for measuring $\mathrm{CO}$ non-invasively, to provide data closely correlated with those of the dye dilution or thermo dilution methods in horses [16].

SV was calculated according to the previous report [16] using an ultrasound imaging system (Logiq TM 500, Yokogawa Medical Systems, Tokyo) with a $2.5 \mathrm{MHz}$ sector-type probe. The left thoracic wall between the 5 th and 6th ribs was scanned by the sound to produce a B-mode image of the aortic sinus, and the cut-surface area at a systolic stage was calculated by measuring the inside diameter of the outflow passage of the left ventricle. The sampling point of the aortic blood flow was immediately above the aortic valve in the center of the ascending aorta. The aortic blood flow was continuously imaged at an incoming angle of $15^{\circ}$ or less against the flow direction of doppler. The typical and distinguished velocity waves of the aortic blood flow in successive 5 strokes were selected from the diagnostic images. Then SV was calculated by multiplication of the time integral value measured by tracing these velocity waves and the cut surface areas of the cardiac outflow passage. In addition, from the wave shape of the aortic blood flow velocity and of electrocardiogram (Base-apex lead), HR, PEP (time from the onset of the QRS complex to the onset of ejection) and ET (time from the onset to the end of ejection) were calculated. PEP and ET can be used as an index of the cardiac contractility in human [25] and horses $[27,29]$. Subsequently the CO, CI, PEP/ET (more accurate indicator of left ventricular function [6]) and SVR were calculated as follows:

$$
\begin{aligned}
& \mathrm{CO}(l / \mathrm{min})=\mathrm{SV}(l) \times \mathrm{HR}(\text { beats } / \mathrm{min}) \\
& \mathrm{CI}(l / \mathrm{min} / \mathrm{kg})=\mathrm{CO}(l) / \text { Body weight }(\mathrm{kg}) \\
& \mathrm{PEP} / \mathrm{ET}=\mathrm{PEP}(\mathrm{msec}) / \mathrm{ET}(\mathrm{msec}) \\
& \mathrm{SVR}\left(\text { dynes } \cdot \mathrm{sec} / \mathrm{cm}^{5}\right) \\
& \quad=60 \times[\mathrm{MAP}(\mathrm{mmHg})-\mathrm{MRAP}(\mathrm{mmHg})] \times 1332 / \\
& \quad[\mathrm{CO}(l / \mathrm{min}) \times 1000][5]
\end{aligned}
$$


Statistics: The data sets of cardiopulmonary measurement were analyzed with repeated measure analysis of variance to determine the effects of anesthesia duration and infusion rate. When appropriate, values between different infusion rates or different measurement time points were examined by Student-Newman-Keuls test. The level of statistical significance was less than 0.05 .

\section{RESULTS}

Anesthesia: Time from the start of $3.0 \mathrm{mg} / \mathrm{kg}$ propofol administration for induction to sternal recumbency in swing-door was 2.4 to 3.0 (mean $\pm \mathrm{SD}, 2.6 \pm 0.2$ ) $\mathrm{min}$. The time required from the end of $3.0 \mathrm{mg} / \mathrm{kg}$ propofol administration to the start of continuous propofol infusion for maintaining anesthesia was 5 to $14(8.8 \pm 3.7) \mathrm{min}$, and during this period, horses were intubated and transported to operation room. The duration of maintaining anesthesia by continuous infusion of propofol was 124 to $131(127.8 \pm 2.9)$ min. The measurement of parameters was performed at approximately 70, 95 and $120 \mathrm{~min}$, respectively, after the start of propofol infusion. No abnormal findings that required emergency treatment were noted in any of the horses during anesthesia.

Respiratory rate and arterial blood gases: Respiratory rate was $6.2 \pm 2.6$ breathes/min under spontaneous breathing at $5 \mathrm{~min}$ after the start of maintenance anesthesia, and apnea of 30-60 sec was observed in two horses. After applying IPPV, $\mathrm{PaCO}_{2}$ was maintained at the targeted level of $45-55 \mathrm{mmHg}$.

Changes of the cardiovascular parameters related to the change of propofol infusion rate: Measurements of cardiovascular variables at three infusion rates are shown in Table 2. Mean HR was in the range of 32.0-32.9 beats/min, showing no significant change. SV decreased with the increase of infusion rate. SV at 0.20 and $0.30 \mathrm{mg} / \mathrm{kg} / \mathrm{min}(703.3$ and $694.7 \mathrm{ml}$, respectively) was significantly lower than that of
$0.14 \mathrm{mg} / \mathrm{kg} / \mathrm{min}(744.7 \mathrm{ml})$. CO and CI were in the ranges of $22.6-23.7 \mathrm{l} / \mathrm{min}$ and $50.5-52.8 \mathrm{ml} / \mathrm{kg} / \mathrm{min}$, respectively. MAP and MRAP were in the range of 96-105 and 6.0-6.7 $\mathrm{mmHg}$, respectively. SVR at $0.30 \mathrm{mg} / \mathrm{kg} / \mathrm{min}(315.9$ dynes $\left.\cdot \mathrm{sec} / \mathrm{cm}^{5}\right)$ was significantly lower than that of $0.20 \mathrm{mg} /$ $\mathrm{kg} / \mathrm{min}\left(350.0\right.$ dynes $\left.\cdot \mathrm{sec} / \mathrm{cm}^{5}\right)$. PEP was prolonged dosedependently, and the value at $0.30 \mathrm{mg} / \mathrm{kg} / \mathrm{min}(163.4 \mathrm{msec})$ was significantly longer than that of $0.14 \mathrm{mg} / \mathrm{kg} / \mathrm{min}(128.4$ $\mathrm{msec})$. ET was in the range of 532.2-554.9 msec. PEP/ET at $0.30 \mathrm{mg} / \mathrm{kg} / \mathrm{min}(0.31)$ was significantly larger than that of $0.14 \mathrm{mg} / \mathrm{kg} / \mathrm{min}(0.23)$.

Changes of the cardiovascular parameters over time during propofol infusion: Chronological changes in cardiovascular variables during maintenance of anesthesia are shown in Table 3. Mean HR increased significantly with time. HR at $120 \mathrm{~min}$ (33.6 beats/min) was significantly higher than that of $70 \mathrm{~min}$ ( 30.9 beats $/ \mathrm{min})$. SV changed within the range of $693.7-727.0 \mathrm{ml}$, showing no significant change. $\mathrm{CO}$ and $\mathrm{CI}$ at $95 \mathrm{~min}(23.4 \mathrm{l} / \mathrm{min}$ and $52.2 \mathrm{ml} / \mathrm{kg} / \mathrm{min}$, respectively) and at $120 \mathrm{~min}(24.4 \mathrm{l} / \mathrm{min}$ and $54.5 \mathrm{ml} / \mathrm{kg} /$ min, respectively) were significantly higher than those of 70 $\min (21.4 \mathrm{l} / \mathrm{min}$ and $47.9 \mathrm{ml} / \mathrm{kg} / \mathrm{min})$. MAP was in the range of 97-104 mmHg. MRAP, SVR, PEP, ET and PEP/ET also showed no significant change.

\section{DISCUSSION}

In TIVA of horses, propofol has been combined with infusion of xylazine [15], medetomidine [3, 4], and ketamine [20] to improve anesthesia quality. However, there have been no definite conclusions yet about the agents to combine with propofol in horses due to problems such as hypoxaemia, hypercapnia etc. Therefore, to collect basic data about propofol for TIVA in horses, anesthesia was maintained with infusion of propofol alone in this research.

Anesthetic induction of horses with propofol alone is dangerous since marked limb paddling movement appears

Table 2. Changes in cardiovascular variables at three infusion rates during propofol anesthesia

\begin{tabular}{|c|c|c|c|}
\hline \multirow{2}{*}{ Variables } & \multicolumn{3}{|c|}{ Infusion rates $(\mathrm{mg} / \mathrm{kg} / \mathrm{min})$} \\
\hline & 0.14 & 0.20 & 0.30 \\
\hline Heart rate (beats/min) & $32.0 \pm 7.9$ & $32.1 \pm 6.0$ & $32.9 \pm 6.1$ \\
\hline Stroke volume $(\mathrm{m} l)$ & $744.7 \pm 38.5$ & $703.3 \pm 39.2^{\mathrm{a})}$ & $694.7 \pm 35.5^{\mathrm{a})}$ \\
\hline Cardiac output $(l / \mathrm{min})$ & $23.7 \pm 5.6$ & $22.6 \pm 4.3$ & $22.9 \pm 4.8$ \\
\hline Cardiac index $(\mathrm{m} l / \mathrm{kg} / \mathrm{min})$ & $52.8 \pm 8.9$ & $50.5 \pm 7.1$ & $51.2 \pm 8.4$ \\
\hline $\begin{array}{l}\text { Mean arterial blood pressure } \\
\quad(\mathrm{mmHg})\end{array}$ & $105 \pm 11$ & $104 \pm 14$ & $96 \pm 15$ \\
\hline $\begin{array}{l}\text { Mean right atrial pressure } \\
(\mathrm{mmHg})\end{array}$ & $6.3 \pm 4.7$ & $6.3 \pm 3.8$ & $6.0 \pm 4.9$ \\
\hline $\begin{array}{l}\text { Systemic vascular resistance } \\
\left(\text { dynes } \cdot \mathrm{sec} / \mathrm{cm}^{5}\right)\end{array}$ & $341.6 \pm 60.0$ & $350.0 \pm 49.4$ & $315.9 \pm 30.9^{b)}$ \\
\hline Pre-ejection period (msec) & $128.4 \pm 33.3$ & $145.7 \pm 36.3$ & $163.4 \pm 47.7^{\mathrm{a})}$ \\
\hline Ejection time (msec) & $554.9 \pm 48.6$ & $547.2 \pm 43.2$ & $532.2 \pm 29.7$ \\
\hline $\begin{array}{l}\text { Pre-ejection period/Ejection time } \\
\quad(\mathrm{PEP} / \mathrm{ET})\end{array}$ & $0.23 \pm 0.06$ & $0.27 \pm 0.05$ & $0.31 \pm 0.08^{\mathrm{a})}$ \\
\hline
\end{tabular}

$p<0.05$. a) versus (vs.) $0.14 \mathrm{mg} / \mathrm{kg} / \mathrm{min}$. b) vs. $0.20 \mathrm{mg} / \mathrm{kg} / \mathrm{min}$. 
Table 3. Chronological changes in cardiovascular variables during propofol anesthesia

\begin{tabular}{|c|c|c|c|}
\hline \multirow{2}{*}{ Variables } & \multicolumn{3}{|c|}{ Duration of propofol infusion (min) } \\
\hline & 70 & 95 & 120 \\
\hline Heart rate (beats/min) & $30.9 \pm 5.8$ & $32.5 \pm 7.4$ & $33.6 \pm 6.7^{\mathrm{a}}$ \\
\hline Stroke volume $(\mathrm{m} l)$ & $693.7 \pm 59.1$ & $722.0 \pm 28.2$ & $727.0 \pm 30.7$ \\
\hline Cardiac output $(l / \mathrm{min})$ & $21.4 \pm 4.3$ & $23.4 \pm 4.9^{\mathrm{a})}$ & $24.4 \pm 5.1^{\mathrm{a}}$ \\
\hline Cardiac index $(\mathrm{m} l / \mathrm{kg} / \mathrm{min})$ & $47.9 \pm 7.4$ & $52.2 \pm 7.7^{\mathrm{a})}$ & $54.5 \pm 7.9^{\mathrm{a})}$ \\
\hline $\begin{array}{l}\text { Mean arterial blood pressure } \\
(\mathrm{mmHg})\end{array}$ & $97 \pm 18$ & $103 \pm 11$ & $104 \pm 12$ \\
\hline $\begin{array}{l}\text { Mean right atrial pressure } \\
(\mathrm{mmHg})\end{array}$ & $6.7 \pm 4.3$ & $6.0 \pm 4.7$ & $6.0 \pm 4.5$ \\
\hline $\begin{array}{l}\text { Systemic vascular resistance } \\
\left(\text { dynes } \cdot \mathrm{sec} / \mathrm{cm}^{5}\right)\end{array}$ & $340.8 \pm 49.6$ & $340.7 \pm 62.7$ & $326.0 \pm 34.4$ \\
\hline Pre-ejection period (msec) & $147.9 \pm 45.0$ & $137.9 \pm 25.3$ & $151.8 \pm 51.5$ \\
\hline Ejection time (msec) & $542.8 \pm 39.1$ & $546.7 \pm 45.2$ & $544.9 \pm 43.0$ \\
\hline $\begin{array}{l}\text { Pre-ejection period/Ejection time } \\
\text { (PEP/ET) }\end{array}$ & $0.27 \pm 0.08$ & $0.25 \pm 0.03$ & $0.38 \pm 0.09$ \\
\hline
\end{tabular}

in lateral recumbency immediately after induction (unpublished data). For this reason, minimal premedication with xylazine alone was performed to ensure the safety of horses and personnel. Therefore, the influence of xylazine cannot be denied in this research. However, cardiovascular parameters were measured at approximately $80 \mathrm{~min}$ or later after xylazine administration. After $80 \mathrm{~min}$ from intravenous administration of $1.0 \mathrm{mg} / \mathrm{kg}$ xylazine, it is known that MAP, CI, SV, SVR and HR showed no significant change [28]. In consequence, the influence of premedication on measurements obtained in this research was presumably small.

It would be reasonable to suppose that the influence of propofol infusion on cardiovascular function would tend to be more pronounced in the latter parts of TIVA. In this research, to control the influence of such time factor, each of 6 possible sequences of 3 different infusion rates was applied to each of 6 horses respectively and randomly. Therefore, it can be considered that the influence of time factors would be evenly distributed throughout the 6 horses. Moreover, any effects attributable to the difference of infusion rate at each measurement time point would also be evenly distributed throughout the 6 horses.

It is known that the change of the arterial propofol concentration in relation to the change of infusion rate plateaued at $15 \mathrm{~min}$ after changing the rate [21]. Therefore, in this research, cardiovascular parameters were measured after maintaining each infusion rate for $20 \mathrm{~min}$.

It is reported that $\mathrm{SV}$ and $\mathrm{CO}$ decreased during propofol anesthesia in human [13], pig [9] and dog [18] similar to other anesthetics. However, there is another report in human where propofol did not influence SV or CO probably because some depressive effects of propofol on cardiovascular system was masked by the effects of increased $\mathrm{PaCO}_{2}$ caused by moderate respiratory impairment [8]. Moreover, in a study of horses, profound hypercapnia at high propofol infusion rate $(0.25 \mathrm{mg} / \mathrm{kg} / \mathrm{min})$ was associated with higher CI $(62 \mathrm{ml} / \mathrm{kg} / \mathrm{min})$, compared with the lower infusion rate
$(0.15 \mathrm{mg} / \mathrm{kg} / \mathrm{min})$ that was associated with lower $\mathrm{PaCO}_{2}$ and CI (35 $\mathrm{ml} / \mathrm{kg} / \mathrm{min})$ [15]. In order to avoid such indirect influence of respiratory depression, IPPV was performed in this research to maintain constant $\mathrm{PaCO}_{2}$ at 45 to $55 \mathrm{mmHg}$. As a result, in contrast with the above report of horses, SV decreased significantly in a dose-dependent manner, although $\mathrm{HR}$ and $\mathrm{CO}$ did not change. Therefore, it was confirmed that propofol infusion depresses cardiac function in horses dose-dependently under the condition without the influence of respiratory depression by itself.

In this research, SV decreased significantly in a dosedependent manner during propofol infusion, however $\mathrm{CO}$ did not decrease. CO is simply calculated by multiplying SV by HR. Therefore, it follows that the decrease in SV was compensated by the slightly increase in HR though HR did not change significantly. The cause of this compensation for decreased SV by slightly increased HR is not clear. However, it is known that propofol dose not impair the baroreceptor reflex sensitivity [8]. Therefore, the cause for which $\mathrm{CO}$ did not change in spite of decrease in SV may include the baroreceptor reflex control of HR.

In this research, although MAP and $\mathrm{CO}$ did not change significantly, MAP tended to decrease, $p=0.088$, and SVR decreased significantly at higher dose. It is reported that the decrease of SVR associated with a central depression of sympathetic outflow resulted in the decrease of arterial pressure during TIVA with propofol [8]. Consequently, also in this research, the decrease of SVR may have influenced MAP in some degree.

In this research, PEP was prolonged and PEP/ET increased significantly with increase of infusion rate. In addition, PEP and ET obtained in this research were longer than those reported in conscious horses, 70 and $480 \mathrm{msec}$, respectively [29]. PEP is known to be prolonged due to increase in afterload and decrease in preload and cardiac contractility $[6,24,30]$. PEP/ET increases due to increased $\mathrm{HR}$ and decrease in preload and cardiac contractility [6, 24]. 
In this research, MRAP, an indicator of preload [5], and HR did not change significantly. SVR, an indicator of afterload, significantly decreased. Therefore, it can be safely said that the significantly prolonged PEP and increased PEP/ET reflect the decrease in cardiac contractility.

In anesthetized horses with sevoflurane, CI, SV and MAP are reported to be $47 \pm 6 \mathrm{ml} / \mathrm{kg} / \mathrm{min}, 619 \pm 70 \mathrm{ml}$ and $65 \pm$ $12 \mathrm{mmHg}$ at $1.5 \mathrm{minimum}$ alveolar concentration (MAC) and $32 \pm 7 \mathrm{ml} / \mathrm{kg} / \mathrm{min}, 419 \pm 91 \mathrm{~m} l$ and $43 \pm 6 \mathrm{mmHg}$ at 2.0 MAC, respectively [1]. The CI, SV and MAP in this research were maintained higher than these values even at the highest infusion rate. On the other hand, the depth of anesthesia produced by 1.2 to $1.4 \mathrm{MAC}$ of inhalation anesthetic is almost equivalent to the depth produced by propofol infusion of $0.14 \mathrm{mg} / \mathrm{kg} / \mathrm{min}$, the lowest rate in this research, [21]. Therefore, CI, SV and MAP in this research were higher than those in horses anesthetized with sevoflurane in comparison at almost the same anesthetic depth.

$\mathrm{SV}$ and MAP did not change, and $\mathrm{HR}, \mathrm{CO}$ and $\mathrm{CI}$ increased significantly with time in this research. From the above, it can be inferred that the accumulation of propofol did not contribute to increased cardiovascular depression in the latter parts of TIVA. As the cause of increase in $\mathrm{HR}, \mathrm{CO}$ and CI with time, the chronological reduction of cardiovascular depressant effect by xylazine used for premedication can not be denied. However, as has been mentioned, the influence of xylazine on measurements was presumably small. Another possible cause of chronological increase in $\mathrm{HR}, \mathrm{CO}$ and $\mathrm{CI}$ is the time-related increase of sympathetic nervous system activity as suggested in inhalation anesthetics [23].

It was found from the result that, during TIVA with propofol of 0.14 to $0.30 \mathrm{mg} / \mathrm{kg} / \mathrm{min}$ in horses, SV decreased dose-dependently caused by the depression of cardiac contractility without CO decrease. Although SVR decreased dose-dependently, MAP did not decrease. Moreover, it is inferred that the degree of cardiovascular depression during TIVA with propofol is less than those of inhalation anesthesia. It is concluded that these results indicate a high safety of TIVA with propofol for clinical applications in horses.

\section{REFERENCES}

1. Aida, H., Mizuno, Y., Hobo, S., Yoshida, K. and Fujinaga, T. 1996. Cardiovascular and pulmonary effects of sevoflurane anesthesia in horses. Vet. Surg. 25: 164-170.

2. Bettschart, W. R., Bowen M. I., Freeman, S. L., Feller, R., Bettschart, R. W., Nolan, A. and Clarke, K. W. 2001. Cardiopulmonary effects of prolonged anesthesia via propofolmedetomidine infusion in ponies. Am. J. Vet. Res. 62: 14281435.

3. Bettschart, W. R., Freeman, S. L., Jaggin, S. N. and Clarke, K. W. 2001. Infusion of a combination of propofol and medetomidine for long-term anesthesia in ponies. Am. J. Vet. Res. 62: 500-507.

4. Bettschart, W. R., Bowen, M. I., Freeman, S. L., Weller, R. and Clarke, K. W. 2003. Medetomidine-ketamine anaesthesia induction followed by medetomidine-propofol in ponies: infusion rates and cardiopulmonary side effects. Equine Vet. J. 35:
308-313.

5. Bonagura, J. D. and Muir, W. W. III 1991. The cardiovascular system. pp. 39-104. In: Equine Anesthesia: Monitoring and Emergency Therapy (Muir, W. W. and Hubbel, J. A. E. eds.), Mosby Year Book, St. Louis.

6. Boon, J. A. 1998. Evaluation of size, function, and hemodynamics. pp. 151-236. In: Manual of Veterinary Echocardiography, Williams \& Wilkins, Pennsylvania.

7. Camu, F., Lauwers, M. and Vanlersberghe, C. 1997. Total Intravenous Anesthesia. pp. 375-392. In: Textbook of Intravenous Anesthesia (White, P. F. ed.), The Williams \& Wilkins Co., London.

8. Claeys, M. A., Gepts, E. and Camu, F. 1988. Haemodynamic changes during anaesthesia induced and maintained with propofol. Br. J. Anaesth. 60: 3-9.

9. Coetzee, A., Fourie, P., Coetzee, J., Badenhorst, E., Rebel, A., Bolliger, C., Uebel, R., Wium, C. and Lombard, C. 1989. Effect of various propofol plasma concentrations on regional myocardial contractility and left ventricular afterload. Anesth. Analg. 69: 473-483.

10. Flaherty, D., Reid, J., Welsh, E., Amonteiro, A. M., Lerche, P. and Nolan, A. 1997. A pharmacodynamic study of propofol or propofol and ketamine infusions in ponies undergoing surgery. Res. Vet. Sci. 62: 179-184.

11. Garcia-Villar, R., Toutain, P. L., Alvinerie, M. and Ruckebusch, Y. 1981. The pharmacokinetics of xylazine hydrochloride: an interspecific study. J. Vet. Pharmacol. Ther. 4: 87-92.

12. Grandy, J. L., Steffey, E. P., Hodgson, D. S. and Woliner, M. J. 1987. Arterial hypotension and the development of postanesthetic myopathy in halothane-anesthetized horses. Am. J. Vet. Res. 48: 192-197.

13. Langley, M. S. and Heel, R. C. 1988. Propofol; a review of its pharmacodynamics and pharmacokinetic properties and use as an intravenous anaesthetic. Drugs 35: 334-372.

14. Lindsay, W. A., Robinson, G. M., Brunson, D. B. and Majors, L. J. 1989. Induction of equine postanesthetic myositis after halothane-induced hypotension. Am. J. Vet. Res. 50: 404-410.

15. Mama, K. R., Pascoe, P. J., Steffey, E. P. and Kollias, B. C. 1998. Comparison of two techniques for total intravenous anesthesia in horses. Am. J. Vet. Res. 59: 1292-1298.

16. Mizuno, Y., Aida, H., Hara, H., Fujinaga, T. and Hagio, M. 1994. Comparison of methods of cardiac output measurements determined by dye dilution, pulsed doppler echocardiography and thermodilution in horses. J. Vet. Med. Sci. 56: 1-5.

17. Muir, W. W. III 1991. Intravenous anesthetics and anesthetic techniques in horses. pp. 281-309. In: Equine Anesthesia: Monitoring and Emergency Therapy (Muir, W. W. and Hubbel, J. A. E. eds.), Mosby Year Book, St. Louis.

18. Nakaigawa, Y., Akazawa, S., Shimizu, R., Ishii, R. and Yamato, R. 1995. Effects of graded infusion rates of propofol on cardiovascular haemodynamics, coronary circulation and myocardial metabolism in dogs. Br. J. Anaesth. 75: 616-621.

19. Nolan, A. M. and Hall, L. W. 1985. Total intravenous anaesthesia in the horse with propofol. Equine Vet. J. 17: 394-398.

20. Nolan, A., Reid, J., Welsh, E., Flaherty, D., McCormack, R. and Monteiro, A. M. 1996. Simultaneous infusions of propofol and ketamine in ponies premedicated with detomidine: a pharmacokinetic study. Res. Vet. Sci. 60: 262-266.

21. Oku, K., Ohta, M., Yamanaka, T., Mizuno, Y. and Fujinaga, T. 2005. The minimum infusion rate (MIR) of propofol for total intravenous anesthesia after premedication with xylazine in horses. J. Vet. Med. Sci. 67: 569-575.

22. Robertson, S. A., Johnston, S. and Beemsterboer, J. 1992. Car- 
diopulmonary, anesthetic, and postanesthetic effects of intravenous infusions of propofol in greyhounds and non-greyhounds. Am. J. Vet. Res. 53: 1027-1032.

23. Steffy, E. P. 1991. Inhalation anesthetics and gases. pp. 352379. In: Equine Anesthesia: Monitoring and Emergency Therapy (Muir, W. W. and Hubbel, J. A. E. eds.), Mosby Year Book, St. Louis.

24. Tournadre, J. P., Muchada, R., Lansiaux, S. and Chassard, D. 1999. Measurements of systolic time intervals using a transoesophageal pulsed echo-Doppler. Br. J. Anaesth. 83: 630-636.

25. Weissler, A. M., Peeler, R. G. and Roehll, W. H. Jr. 1961. Relationships between left ventricular ejection time, stroke volume, and heart rate in normal individuals and patients with cardiovascular disease. Am. Heart J. 62: 367-378.

26. White, P. F. and Smith, I. 1997. Propofol. pp. 111-152. In: Textbook of Intravenous Anesthesia (White, P. F. ed.), The Williams \& Wilkins Co., London.
27. Yamanaka, T., Oku, K., Koyama, H. and Mizuno, Y. 2001. Time-related changes of the cardiovascular system during maintenance anesthesia with sevoflurane and isoflurane in horses. J. Vet. Med. Sci. 63: 527-532.

28. Yamashita, K., Tsubakishita, S., Futaoka S., Ueda, I., Hamaguchi, H., Seno, T., Katoh, S., Izumisawa, Y., Kotani, T. and Muir, W. W. 2000. Cardiovascular effects of medetomidine, detomidine and xylazine in horses. J. Vet. Med. Sci. 62: 10251032.

29. Young, L. E. and Scott, G. R. 1998. Measurement of cardiac function by transthoracic echocardiography: day to day variability and repeatability in normal Thoroughbred horses. Equine Vet. J. 30: 117-122.

30. Young, L. E., Blissitt, K. J., Clutton, R. E. and Molony, V. 1998. Haemodynamic effects of a sixty minute infusion of dopamine hydrochloride in horses anaesthetised with halothane. Equine Vet. J. 30: 310-316. 